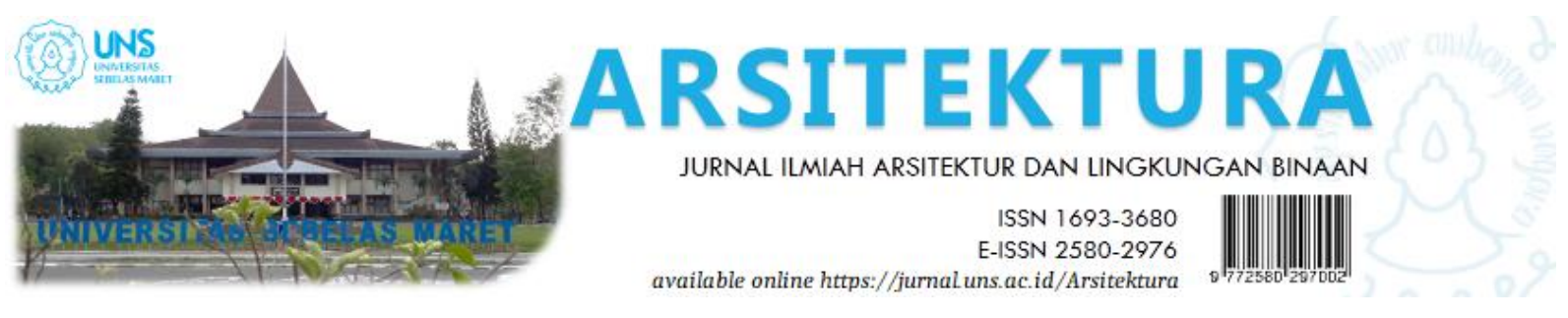

Volume 19 Issue 2 October 2021, pages:307-316

\title{
Identifikasi Peran Masyarakat dalam Pembangunan Kampung Kota Berkelanjutan
}

\author{
Identification of Community Role \\ in Sustainable Urban Kampung Development
}

\author{
Sri Yuliani ${ }^{{ }^{*}}$, Purwanto Setyo Nugroho ${ }^{2}$, Tri Yuni Iswati ${ }^{3}$ \\ Architecture Department, Engineering Faculty, Universitas Sebelas Maret ${ }^{1 *}$ \\ sriyuliani71@staff.uns.ac.id \\ Architecture Department, Engineering Faculty, Universitas Sebelas Maret ${ }^{2}$ \\ Architecture Department, Engineering Faculty, Universitas Sebelas Maret ${ }^{3}$
}

DOI: https://doi.org/10.20961/arst.v19i2.55997

Received:October 26,2021 Revised:October 27,2021 Accepted:October 27,2021 Available online:October 30,2021

\begin{abstract}
Sustainable City Development can be achieved with the active role of actors in development activities, one of which is the role of the community. This study aims to identify the role of the urban Kampung community in the sustainable development of Kampung Kota. The research location is in the city of Surakarta with a sample of Kampung Gendingan RW 15, Kelurahan Jebres, Kecamatan (district) Jebres. The study used qualitative methods, through observation, interviews and discussion groups with swot analysis. The results showed that the role of the community in the development of the urban village can be applied to the participation of concept formulation, design and management. The three roles of the urban village community will be able to form a unique and sustainable village model.
\end{abstract}

Keywords: identification of community role; sustainable development; urban kampung; kampung community; sustainable kampung

\section{PENDAHULUAN}

Latar belakang penelitian berangkat dari tujuan Pembangunan Berkelanjutan yang mengadopsi maklumat Sustainable Development's Goal terdiri dari 17 aspek pembangunan. Aspek yang menjadi fokus penelitian adalah aspek ke sebelas yakni Kota dan Permukiman Berkelanjutan. Fokus ini mempertimbangkan fenomena bahwa setengah dari populasi dunia, menempati wilayah perkotaan. Pertumbuhan kota yang sangat cepat, berakibat memberikan dampak pada permasalahan perkotaan. Salah satu permasalahan perkotaan diantaranya peningkatan kesenjangan permukiman yang sering terjadi di wilayah perkotaan, yakni adanya perbedaan kualitas permukiman yang menyebabkan kurang meratanya penataan dan ketercapaian standart rumah layak huni pada permukiman. Permasalahan permukiman menjadi pertimbangan dalam mendorong pembangunan kota berkelanjutan dengan menyasar pada perbaikan permukiman dan terciptanya perumahan yang aman dan terjangkau didukung oleh lingkungan sehat yang mendukung. Implementasi pembangunan 
permukiman tertuang dalam target utama SDGs Indonesia adalah pada tahun 2030, yakni menjamin akses bagi semua masyarakat terhadap perumahan yang layak, aman, terjangkau, dan pelayanan dasar, serta menata kawasan kumuh. Selain itu, dicanangkan pula upaya untuk perencanaan penanganan permukiman berkelanjutan, dan mengurangi dampak lingkungan perkotaan dengan memberikan perhatian khusus pada kualitas udara.

Pembangunan kota berkelanjutan di Indonesia saat ini perlu berorientasi dengan pembangunan kampung (Roychansyah \& Diwangkari, 2009). Diperkuat oleh Prayitno dkk bahwa dinamika perkembangan kota sudah pasti mempengaruhi perkembangan kampung sebagai bagian dari kota (Prayitno \& Qomarun, 2007). Untuk itu, pembangunan kota yang berkelanjutan sudah selayaknya juga menyasar target pembangunan kampung dan komponen kampung yang di dalamnya.

Kampung adalah kawasan secara visual dalam lansekap perkotaan Indonesia, terdiri dari permukiman tradisional yang berkembang akibat pemekaran kota, dan seolah terperangkap di dalam dinamika perkembangan perkotaan dan berubah menjadi kampung kota (Nur'aini, 2017; Putra et al., 2019; Sudarwanto B, Hardiman G, 2018). Unsur permukiman tradisional di perkotaan dapat dipandang sebagai potensi keunikan yang perlu dilestarikan. Namun di sisi lain, pola tradisional yang kurang mengapresiasi lingkungan akan menjadi kendala dalam mewujudkan pembangunan berkelanjutan. Potensi dan kendala dalam pola tradisional permukiman menjadi pertimbangan yang perlu dikelola agar dapat mendukung pembangunan kampung kota berkelanjutan.

Keberhasilan pembangunan kampung kota tidak terlepas dari peran aktif masyarakat. Penelitian sebelumnya membahas keterlibatan masyarakat dalam keberlanjutan ruang hijau menyimpulkan bahwa ruang hijau dapat berkelanjutan dengan melibatkan aspirasi dan dukungan masyarakat sekitarnya (Yuliani \& Setyaningsih, 2018). Lebih lanjut diungkapkan bahwa melalui studi komparasi diperoleh perbandingan antara ruang hijau kota yang dibangun berbasis bottom up lebih berhasil dibandingkan dengan top down. Hal yang paling utama, ternyata karena hubungan batin kepemilikan yang dirasakan masyarakat, sehingga berusaha untuk merawat dan memperbaiki fasilitas yang disediakan. Ditambahkan pula bahwa peran masyarakat juga penting dalam keberhasilan permukiman sehat, bersih dan efisien, seperti yang telah dihasilkan oleh penelitian selanjutnya (Yuliani et al., 2020). Masyarakat sebagai pelaku primer dalam permukiman akan menentukan kualitas hunian masing-masing, baik secara individu maupun kolektif. Pada beberapa kasus rumah susun yang terawat dengan baik, namun ada juga yang kurang mendapatkan perawatan dari masyarakat penghuninya. Demikian juga untuk kasus penanganan permukiman kumuh, apabila ditelusuri lebih dalam, ternyata bukan semata-mata karena faktor ekonomi, pendidikan atau status sosial, namun cenderung lebih karena faktor pola atau gaya hidup dan kesadaran mengapresiasi hunian yang sehat dan ramah lingkungan.

Terkait dengan arah konsep pembangunan kampung kota, penelitian lain oleh B. Putra yang fokus pada aspek place, space and identity through greening di kampung kota, menemukan kesimpulan bahwa pentingnya masyarakat dalam proses pembuatan konsep ruang di kampung kota (Putra et al., 2019). Ruang kampung kota yang didesain dengan aplikasi elemen hijau akan dapat berkelanjutan apabila masyarakat kampung dilibatkan dalam menyusun konsep ruang.

Dasar pertimbangan lain dalam penentuan konsep pembangunan kampung kota, melalui penelitian terdahulu menunjukkan bahwa pentingnya pembangunan kampung kota mengikuti kebutuhan dan gaya hidup masyarakat. generasi milenial (Sihombing et al., 2020), terutama pada kampung dengan dominasi usia pada kelompok milenial. Hal ini disebabkan oleh populasi generasi milenial yang bermukim di kampung, sehingga menyebabkan perubahan pola, bentuk dan wajah kampung. Perubahan dapat terjadi pada struktur dan tata letak serta peruntukan ruang pada saat dilakukan zonasi.

Kampung kota yang mempunyai potensi kuat perlu dikelola dengan mengedapankan aspek pelestarian dan keberlanjutan. Penelitian yang 
dilakukan oleh B. Putra terkait aspek elemen hijau pada ruang di kampung kota, menemukan kesimpulan bahwa pentingnya masyarakat dalam proses pembuatan konsep ruang di kampung kota agar pembangunan kampung kota senantiasa terawat secara konsisten (Putra et al., 2019).

Aspek berikutnya dalam pembangunan kampung kota agar dapat berhasil adalah konsep lokalitas dengan mempertimbangkan potensi keunikan yang dapat menjadi gaya tarik dan bersifat dinamis. Unsur lokalitas dapat digali dari karakter spesifik kampung kota, diantaranya terkait sosial budaya, ekonomi, topografi, potensi pariwisata, arsitektur dan ekologi kampung. Salah satu contoh, menghadirkan konsep arsitektur dan ekologi dengan menghijaukan Kampung Kota dapat menjadi salah satu daya tarik yang bermanfaat strategis (Břiza, 2019; Fahmy et al., 2017; Setyaningsih et al., 2015; Treija et al., 2013).

Tujuan penelitian adalah mengidentifikasi peran yang strategis dilakukan oleh masyarakat dalam pembangunan berkelanjutan. Manfaat penelitian untuk memberikan gambaran potensi masyarakat, sehingga dapat dilibatkan dalam pembangunan berkelanjutan secara tepat waktu, tepat tempat dan tepat peran.

Berdasarkan pertimbangan pentingnya peran masyarakat dalam pembangunan berkelanjutan, namun belum banyak penelitian arsitektur yang membahas secara detil peran masyarakat yang diperlukan dalam pembangunan berkelanjutan, maka penelitian ini fokus pada identifikasi peran masyarakat Kampung Kota dalam berpartisipasi aktif untuk mewujudkan pembangunan berkelanjutan.

\section{METODE}

Penelitian menggunakan metode kualitatif deskriptif. Tahapan penelitian ditentukan berturut-turut dalam empat tahapan. Tahap pertama, melakukan observasi secara mendalam pada obyek penelitian secara menyeluruh. Tahap kedua, melakukan wawancara secara khusus dan secara umum untuk menjajaki peran masyarakat dalam pembangunan kampung kota. Tahap ketiga, melalukan kelompok diskusi untuk membahas antara peran masyarakat dan kendala maupun keberhasilan yang diperoleh dalam pembangunan kampung. Tahap kelima, melakukan analisis swot (strengths, weakness, opportunities, threats) atau kekepan (kekuatan, kelemahan, potensi dan ancaman) yang mempertimbangkan dari data yang diperoleh sebelumnya. Tahapan analisis ini menghasilkan temuan penelitian yakni identifikasi peran masyarakat yang ideal dan dapat mendukung pembangunan berkelanjutan pada kampung kota.

Lokasi penelitian mengambil sampai wilayah Kampung Gendingan RW 15 Kelurahan Jebres Kecamatan Jebres Kota Surakarta, seperti pada gambar 1. Lokasi ini berada di antara institusi besar yakni Universitas Sebelas Maret, Pusat Budaya Jawa Tengah dan Institut Seni Indonesia Surakarta.

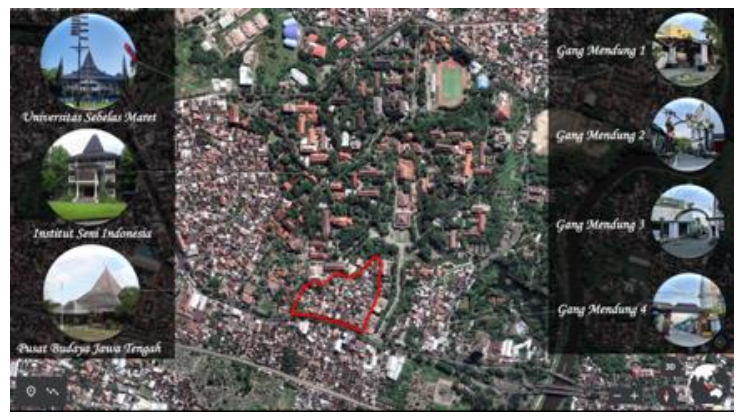

Gambar 1. Lokasi penelitian, gambar lebih besar di lampiran.

Lokasi penelitian juga sangat strategis berada di sepanjang jalan raya yang menghubungkan antara Propinsi Jawa Tengah dengan Propinsi Jawa Timur. Keberadaan lokasi ini akan menajdi ikon Kota Surakarta bahkan ikon Propinsi Jawa Tengah. Wilayah Kampung Gendingan RW 15 apabila ditata dengan ikonik, tentunya akan memiliki daya tarik yang kuat.

\section{HASIL DAN PEMBAHASAN}

Pembangunan Kampung Kota dikembangkan dengan mempertimbangkan peluang dan potensi kampung.

Penelitian kualitatif dengan tema Kampung Kota berkelanjutan ini fokus pada dua sudut pandang posisi strategis kampung kota. Kampung Gendingan RW 15 berada pada 
posisi strategis Universitas Sebelas Maret dan Kota Surakarta.

Pembahasan dimulai dari sudut pandang pertama, posisi strategis Kampung Gendingan terhadap beberapa Lembaga Pendidikan terbesar di Kota Surakarta. Lokasi kampung secara tepat berada di sebelah barat Kampus Universitas Sebelas Maret Kentingan, dibatasi dengan jalan lingkungan yang dinamakan Gang Mendung I, II, III dan IV seperti pada gambar 2.

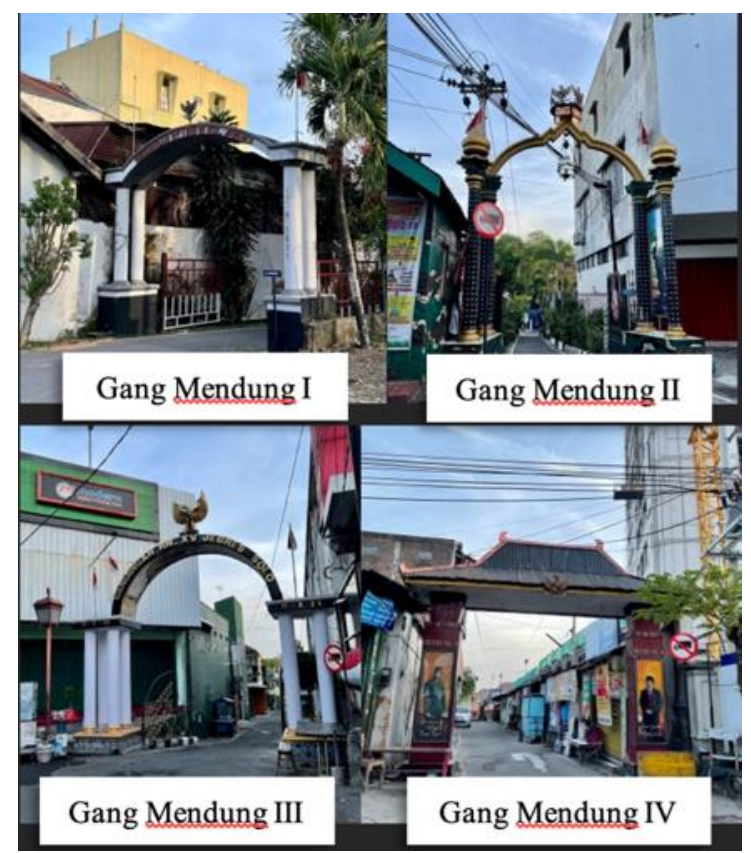

Gambar 2. Wajah Kampung Gendingan RW 15

Kekuatan yang dimiliki wilayah Kampung Gendingan RW 15 adalah letak geografis kampung, merupakan kampung terdekat dibandingkan dengan kampung yang lain. Kelemahan kampung diidentifikasi adanya kontur atau kondisi topografi kampung yang menurun ke dalam, sehingga dari luar terlihat datar, namun ketika memasuki kampung, jalan lingkungan menurun terus hingga mencapai selisih ketinggian sekitar 2-7 meter. Kekuatan dan kelemahan kampung Gendingan RW 15 tidak merata pada setiap RT (Rukun Tetangga), dimana diantara ketiga RT yakni RT 1, RT 2 dan RT 3, yang memiliki hubungan paling erat dengan keberadaan kampus Universitas Sebelas Maret adalah RT 2. Berdasarkan pertimbangan posisi yang strategis, wajah RT 2 yakni Gang Mendung 4, menjadi sebuah letak yang menguntungkan, namun sekaligus menerima beban tertinggi disbandingkan dengan RT dan Gang Mendung yang lain. Fasade Gapuro secara eksisting berbeda dengan berderet pedagang kaki lima di belakang gapura dan sekitarnya, seperti pada Gambar 3.

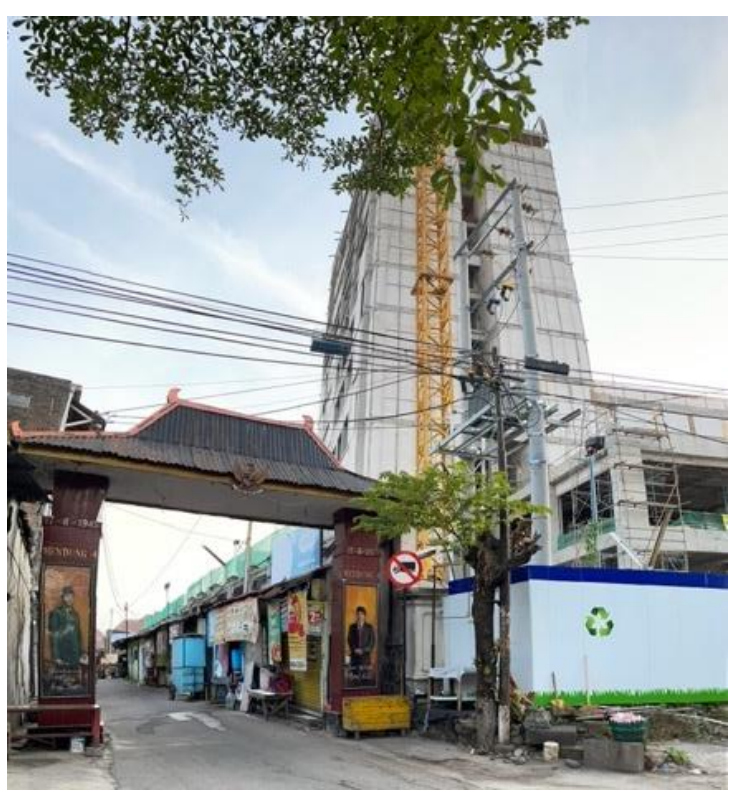

Gambar 3. Tampilan Gang Mendung IV dikelilingi pedagang kaki lima yang menempel dinding UNS.

Potensi yang dimiliki kampung adalah berpeluang menjadi wilayah yang berinteraksi kuat dengan Kampus Universitas Sebelas Maret, diantaranya sebagai akomodasi, transportasi lokal dan warung makan. Hambatan atau kendala yang dapat bisa menjadi ancaman kampung adalah, semakin banyak aktifitas dalam kampung sehingga berdampak pada faktor keamanan dan kenyamanan warga masyarakat. Selain itu, akan juga timbul masalah lingkungan, yakni sampah, berkurangnya ruang komunal karena kehadiran PKL (pedagang kaki lima), bahkan akan menjadi dampak kekumuhan wajah kampung.

Kondisi dan situasi pada pembahasan pertama, dalam skala mikro, menjadi dasar pertimbangan untuk menganalisis peran masyarakat terhadap letak strategis kampung. Peran masyarakat sebagai respon dari posisi strategis terhadap Universitas Sebelas Maret direlevansikan dengan analisis swot diperoleh hasil bahwa masyarakat cenderung memberikan nilai positif terhadap kekuatan dan peluang yang dimiliki oleh wilayah 
Kampung Gendingan. Nilai positif yang ditunjukkan adalah masyarakat bersemangat untuk membangun rumah dengan bangunan yang difungsikan untuk akomodasi yakni kos mahasiswa maupun karyawan dan dosen. Selain itu juga adanya warung makan, toko kebutuhan sehari-hari dan laundry yang berkembang seiring dengan jumlah pendatang yang berdomisili sementara. Sedangkan respon masyarakat terhadap hambatan yang mengancam kampung, terindikasi tidak merata. Artinya, ada sebagian masyarakat yang sudah memahami dan berusaha untuk menjaga lingkungan kampung dengan bijak, walau hanya dilakukan secara mandiri di rumah atau sekitar huniannya. Sebagian masyarakat lain, ada juga yang telah memahami namun belum banyak melakukan kontribusi yang riil. Sedangkan sebagian kecil lainnya masih terindikasi kurang mengapresiasi lingkungan dengan melakukan kegiatan yang kurang ramah lingkungan. Pembangunan pada area komunal yang merupakan akses publik diabaikan dengan berdirinya beberapa kios pedagang kaki lima bersifat permanen. Hal ini memberikan dampak berkurangnya estetika kampung dan beban lingkungan yang secara ekologis akan mempengaruhi lingkungan kampung.

Perbedaan respon masyarakat terhadap peran dan sensitivitas dalam pembangunan lingkungan disebabkan oleh beberapa faktor yakni tingkat pendidikan, faktor ekonomi dan gaya hidup.

Pembahasan kedua, dalam skala makro yakni kajian posisi strategis kampung terhadap Kota Surakarta. Kedudukan kampung kota tidak terlepas dari lokasi dan perkembangan kota secara umum. Kota Surakarta yang terdiri dari lima kecamatan, mempunyai keragaman potensi setiap kecamatan. Demikian juga di Kecamatan Jebres, secara spatial pada kampung Gendingan RW 15 yang berlokasi pada wilayah perbatasan Jawa Tengah dan Jawa Timur. Wilayah kampung berada di sebelah utara Jalan Ir. Sutami, merupakan wilayah pinggir Kota Surakarta, menghubungkan antara Jawa Tengah dan Jawa Timur, sangat strategis sebagai wajah kota, seperti pada gambar 4 .

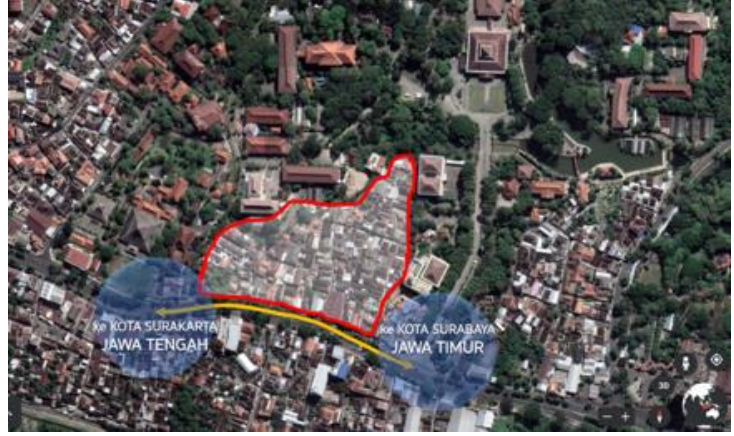

Gambar 4. Lokasi kampung sebagai penghubung antara Propinsi Jawa Tengah dan Jawa Timur.

Kekuatan Kampung Gendingan RW 15 yaitu memiliki posisi pada area yang strategis menghubungkan wilayah antar propinsi, dengan posisi traffic light yang persis berada di area ini, membuat wajah kampung akan mudah dipandang dan berpotensi didesain dengan keunikan yang berciri khusus. Ketika kampung tidak dikelola dengan baik, wajah kampung akan menjadi kelemahan yang berdampak pada visual wilayah yang kurang estetis.

Potensi kampung ditinjau dari skala Kota Surakarta, berpeluang menjadi wilayah ikonik yang memberikan penampilan menarik sebagai cirikhas Kota Surakarta. Namun, ancaman dapat menjadi kendala dimana jalur lalu lintas di wilayah ini akan semakin ramai dan menimbulkan kemacetan.

Penelitian menemukan bahwa dalam skala Kota Surakarta, masyarakat masih belum banyak memberikan respon bagaimana strategisnya wilayah kampung tersebut. Kekuatan dan potensi wilayah kampung belum banyak dimanfaatkan, sedangkan kelemahan dan ancaman dalam skala kota juga belum dapat dirasakan oleh masyarakat kampung kota. Respon masyarakat cenderung dari masyarakat luar yang merupakan investor yang membeli atau menyewa lahan di wilayah kampung Gendingan RW 15.

Analisis lebih lanjut dari kedua pembahasan, menunjukkan bahwa sejauh ini masyarakat kampung masih cenderung merespon dan memanfaatkan kekuatan dan potensi dalam skala mikro. Masyarakat terlihat mempunyai respon yang cepat ketika area dekatnya diselenggarakan suatu kegiatan yang berpotensi mengundang khalayak. Respon yang mucul diantaranya turut memanfaatkan 
kegiatan dengan berjualan dan penertiban jalan lalu lintas sekitar kampung, secara spontan. Model kegiatan seperti ini merupakan upaya pengelolaan yang bersifat temporatif. Sedangkan upaya pengelolaan yang lebih permanen dan terarah belum diorganisasi dengan baik. Hal ini berbeda dengan kegiatan yang bersifat makro, dimana sering kali masyarakat berduyun-duyun hadir dalam kegiatan yang diagendakan dari pemerintah daerah atau kota. Kehadiran yang serentak terlihat diorganisasi melalui perangkat kampung karena himbauan dari pemerintah daerah seperti kelurahan atau kecamatan atau unsur lain.

Berdasarkan analisis swot terhadap peran masyarakat dalam pembangunan kampung Gendingan RW 15 Kelurahan Jebres Kecamatan Jebres Kota Surakarta, maka penelitian menemukan suatu peran yang bersifat berjenjang sesuai dengan kedudukan masyarakat sebagai pengurus dan warga kampung. Sebagai pengurus kampung, mulai dari tingkat RT hingga RW, masyarakat ini berpotensi menjadi quality control, yakni satuan petugas yang melakukan kontrol terhadap ruang-ruang komunal secara terusmenerus. Tugas kontrol meliputi pengawasan penggunaan ruang komunal, pemeriksaan dan perawatan. Sedangkan masyarakat sebagai warga kampung, mempunyai tugas untuk membantu dan mematuhi regulasi setempat, tidak menggunakan ruang komunal secara individu tanpa mengindahkan kepentingan masyarakat lainnya. Kedua lapisan masyarakat ini harus dapat menjaga kebersamaan secara berkelanjutan, agar tercipta kampung yang sehat, asri dan ekologis. Beberapa hal yang utama dalam pembangunan kampung harus dimusyawarahkan meliputi sistem keamanan, ketertiban, pola pengelolaan utilitas lingkungan yang mencakup drainase, ruang hijau dan ruang komunal.

Konsep pembangunan kampung merupakan konsep yang sangat strategis di Indonesia sejalan dengan penelitian Roychansyah dkk (Roychansyah \& Diwangkari, 2009), demikian juga kampung Gendingan yang memiliki posisi dan kedudukan yang strategis dipandang dari skala makro dan mikro, memerlukan suatu konsep yang menyatu dengan Kota Surakarta dengan dukungan wilayah terdekat Universitas
Sebelas Maret. Dinamika perkembangan kampung sebagai bagian penting dari kota seperti pada penelitian yang telah dilakukan oleh Prayitno dkk (Prayitno \& Qomarun, 2007), maka konsep pembangunan kampung yang tepat untuk kampung Gendingan adalah konsep pembangunan yang berkelanjutan dengan mempertimbangkan factor ekologis kampung. Kampung Gendingan yang telah mengalami perubahan bentuk dan fungsi merupakan respon dari tuntutan pembangunan, hal ini menjadi akibat dari perkembangan kota terutama untuk penataan kawasan secara visual dalam lansekap perkotaan Indonesia, seperti dalam penelitian sebelumnya oleh Putra dkk, dimana kampung terdiri dari permukiman tradisional yang berkembang akibat pemekaran kota, dan seolah terperangkap di dalam dinamika perkembangan perkotaan dan berubah menjadi kampung kota (Nur'aini, 2017; Putra et al., 2019; Sudarwanto B, Hardiman G, 2018).

Untuk meraih keberhasilan pembangunan kampung Gendingan RW 15, perlu mengakomodasi peran aktif masyarakat dalam pembangunan. Sejalan dengan penelitian sebelumnya membahas keterlibatan masyarakat dalam keberlanjutan ruang hijau menyimpulkan bahwa ruang hijau dapat berkelanjutan dengan melibatkan aspirasi dan dukungan masyarakat sekitarnya (Yuliani \& Setyaningsih, 2018). Penelitian sependapat bahwa peran masyarakat juga penting dalam keberhasilan permukiman sehat, bersih dan efisien (Yuliani et al., 2020).

Salah satu konsep pembangunan kampung yang telah berhasil dan berkelanjutan diantaranya aplikasi elemen hijau pada konsep ruang (Putra et al., 2019), membuka peluang dalam penyusunan konsep kampung Gendingan agar diolah dengan penyajian elemen hijau pada ruang komunal dengan melibatkan masyarakat kampung.

Dasar pertimbangan lain dalam penentuan konsep pembangunan kampung Gendingan melalui penelitian terdahulu menunjukkan bahwa pentingnya pembangunan kampung kota mengikuti kebutuhan dan gaya hidup masyarakat. generasi milenial (Sihombing et al., 2020), dapat menjadi kombinasi konsep kampung yang memberikan warna kekinian 
untuk kampung Gendingan yang memang secara fisik dan historis tidak dijumpai cagar budaya atau riwayat sejarah yang menjadi pertimbangan.

Aspek pembangunan kampung kota lainnya, adalah konsep lokalitas dengan mempertimbangkan potensi keunikan yang dapat menjadi gaya tarik dan bersifat dinamis (Břiza, 2019; Fahmy et al., 2017; Setyaningsih et al., 2015; Treija et al., 2013), untuk itu ciri yang dilekatkan pada kampung Gendingan RW lebih sesuai dengan kampung ekologis, yakni sebuah kampung yang bertahan dengan meguatkan nilai ekologis kampung di tengah himoitan pembangunan.

Konsep desain kampung ekologis menghadirkan elemen hijau yang ditata kekinian dengan memberikan ruang-ruang dan sudut sebagaian spot foto dan menikmati sejuk dan rindangnya pohon dan tanaman yang dipadukan dengan kebutuhan milenial yakni hot spot atau ruang internet, seperti contoh pada gambar 5, 6, 7 dan 8 .

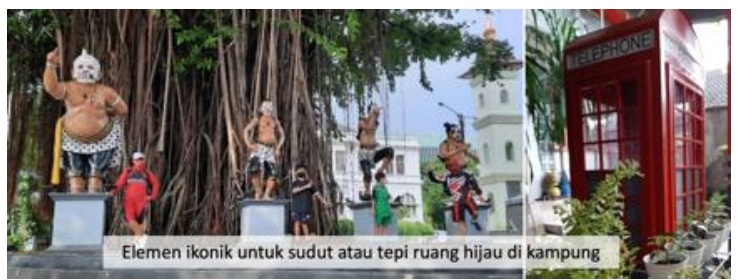

Gambar 5. Contoh furniture street ikonik pada ruang komunal kampung.

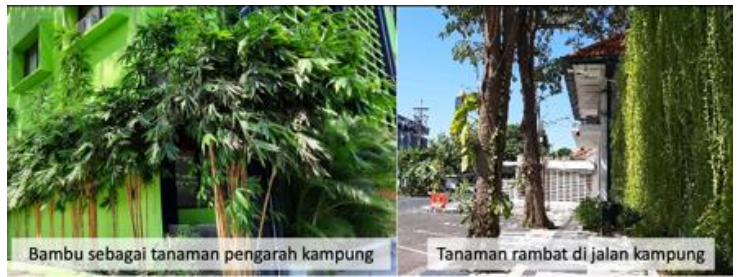

Gambar 6. Contoh tanaman rindang penghias jalan kampung.

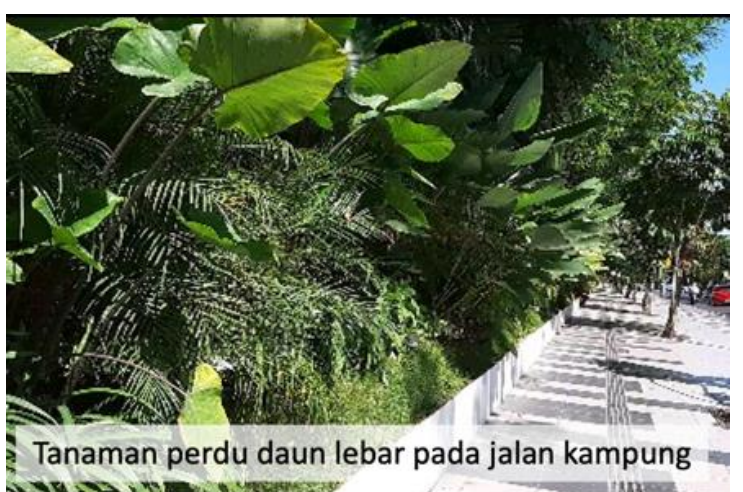

Gambar 7. Contoh tanaman perdu penghias jalan kampung.

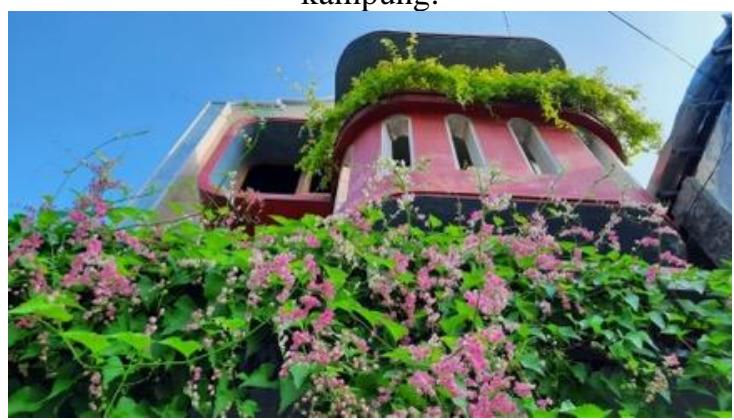

Gambar 8. Contoh tanaman rambat untuk hunian di kampung.

Temuan penelitian mengidentifikasi ada tiga peran yang strategis dilakukan oleh masyarakat dalam pembangunan berkelanjutan, yakni sebagai penyusun konsep, peran aktif dalam pembangunan melalui penentuan ide rancangan dan peran aktif dalam pengelolaan kampung. Kebaruan yang dikembangkan dari penelitian ini adalah unsur keterpaduan peran dan konsep pembangunan kampung ekologis dengan apllikasi elemen hijau berkarakter kekinian agar pembangunan kampung menjadi ikon menarik sehingga tercapai kampung yang lestari, dinamis dan berkelanjutan.

\section{KESIMPULAN}

Penelitian menyimpulkan bahwa peran masyarakat dalam pembangunan kampung kota dapat secara berkelanjutan perlu untuk dimotivasi dan dijaga secara terus-menerus. Program pembangunan berbasis masyarakat yakni bottom up, akan lebih berhasil dan berjalan lancar secara berkelanjutan mendukung pembangunan kampung kota. Peran masyarakat yang potensial dalam pembangunan kota berkelanjutan meliputi: peran dalam menyusun konsep dan strategi, peran dalam menentukan desain atau perancangan, dan peran sebagai pengelola lingkungan kampung kota.

Peran masyarakat dalam ketiga posisi tersebut sebaiknya mempertimbangkan karakteristik masyarakat, usia dan potensi kampung kota.

\section{UCAPAN TERIMAKASIH}

Terimakasih kepada masyarakat Kampung Gendingan RW 15 yang telah banyak 
mendukung dengan memberikan informasi yang dibutuhkan dalam penelitian.

\section{REFERENSI}

Břiza, L. (2019). The Importance of green roofs and Sustainable development. IOP Conference Series: Materials Science and Engineering, 566(1). https://doi.org/10.1088/1757$899 \mathrm{X} / 566 / 1 / 012003$

Fahmy, M., El-hady, H., Mahdy, M., \& Abdelalim, M. F. (2017). On the green adaptation of urban developments in Egypt; predicting community future energy efficiency using coupled outdoorindoor simulations. Energy \& Buildings, 153 ,

241-261. https://doi.org/10.1016/j.enbuild.2017.08. 008

Nur'aini, R. D. (2017). Analisis Konsep Green Roof Pada Kampus School of Art, Design and. Nalars, 16(2), 161-168.

Prayitno, B., \& Qomarun, Q. (2007). Morfologi Kota Solo (Tahun 1500-2000). DIMENSI (Jurnal Teknik Arsitektur), 35(1), 80-87. https://doi.org/10.9744/dimensi.35.1.8087

Putra, B. D., Horne, R., \& Hurley, J. (2019). Place, space and identity through greening in kampung kota. Journal of Regional and City Planning, 30(3), 211223.

https://doi.org/10.5614/jpwk.2019.30.3.3

Roychansyah, M., \& Diwangkari, A. (2009). Kampung Oriented Development Model : A Rapid Appraisal of Local Communities. Informal Settlements and Affordable Housing, 2(11), 119-134.

Setyaningsih, W., Iswati, T. Y., Sri Yuliani, Nuryanti, W., Prayitno, B., \& Sarwadi, A. (2015). Low-Impact-Development as an Implementation of the Eco-GreenTourism Concept to Develop Kampung towards Sustainable City. Procedia Social and Behavioral Sciences, 179, 109-117.

https://doi.org/10.1016/j.sbspro.2015.02. 414

Sihombing, A., Rahardja, A. A., \& Gabe, R. T. (2020). The Role of Millennial Urban Lifestyles in the Transformation of
Kampung Kota in Indonesia. Environment and Urbanization ASIA, 11(1). https://doi.org/10.1177/09754253209062 88

Sudarwanto B, Hardiman G, S. A. (2018). The uniqueness and complexity of kampung city Bustaman Semarang Indonesia The uniqueness and complexity of kampung city Bustaman Semarang Indonesia. IOP Conference Series: Earth and Environmental Science.

Treija, S., Bratuškins, U., \& Bondars, E. (2013). Green open space in large scale housing estates: a place for challenge Green Open Space in Large Scale Housing Estates : a Place for Challenge. November 2014, 37-41. https://doi.org/10.3846/20297955.2012.7 53981

Yuliani, S., Hardiman, G., \& Setyowati, E. (2020). Green - Roof: The Role of Community in the Substitution of Green Space toward Sustainable Development. Sustainability (Switzerland), 12, 1429. https://doi.org/10.3390/su12041429

Yuliani, S., \& Setyaningsih, W. (2018). The Community Role in Green Area Sustainability as a Model of Energyefficient Buildings in the Humid Tropical Region. IOP Conference Series: Earth and Environmental Science. https://doi.org/10.1088/17551315/213/1/012010 
Lampiran

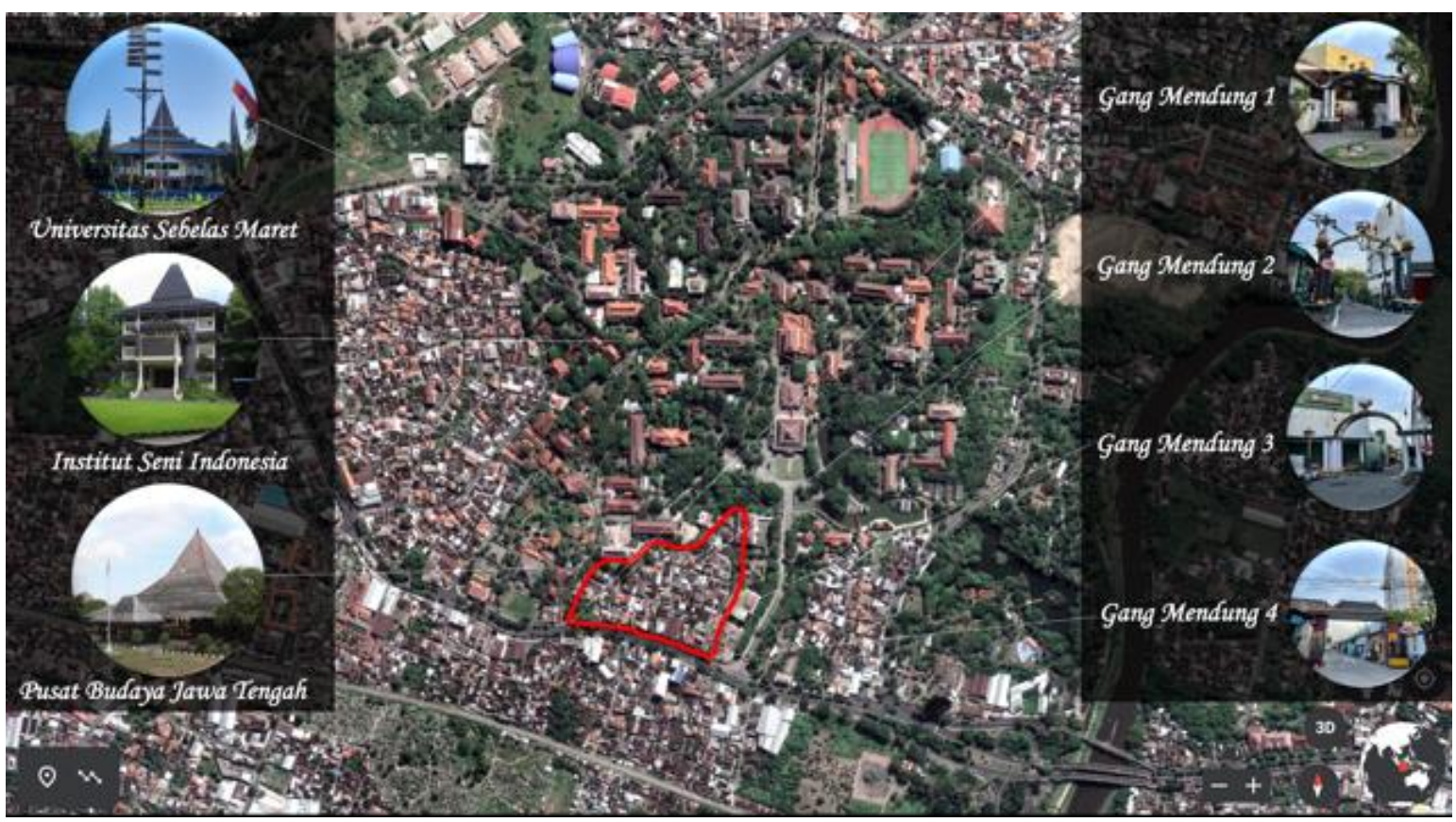

Gambar 9. Lokasi penelitian

\section{PETA KELURAHAN JEBRES}

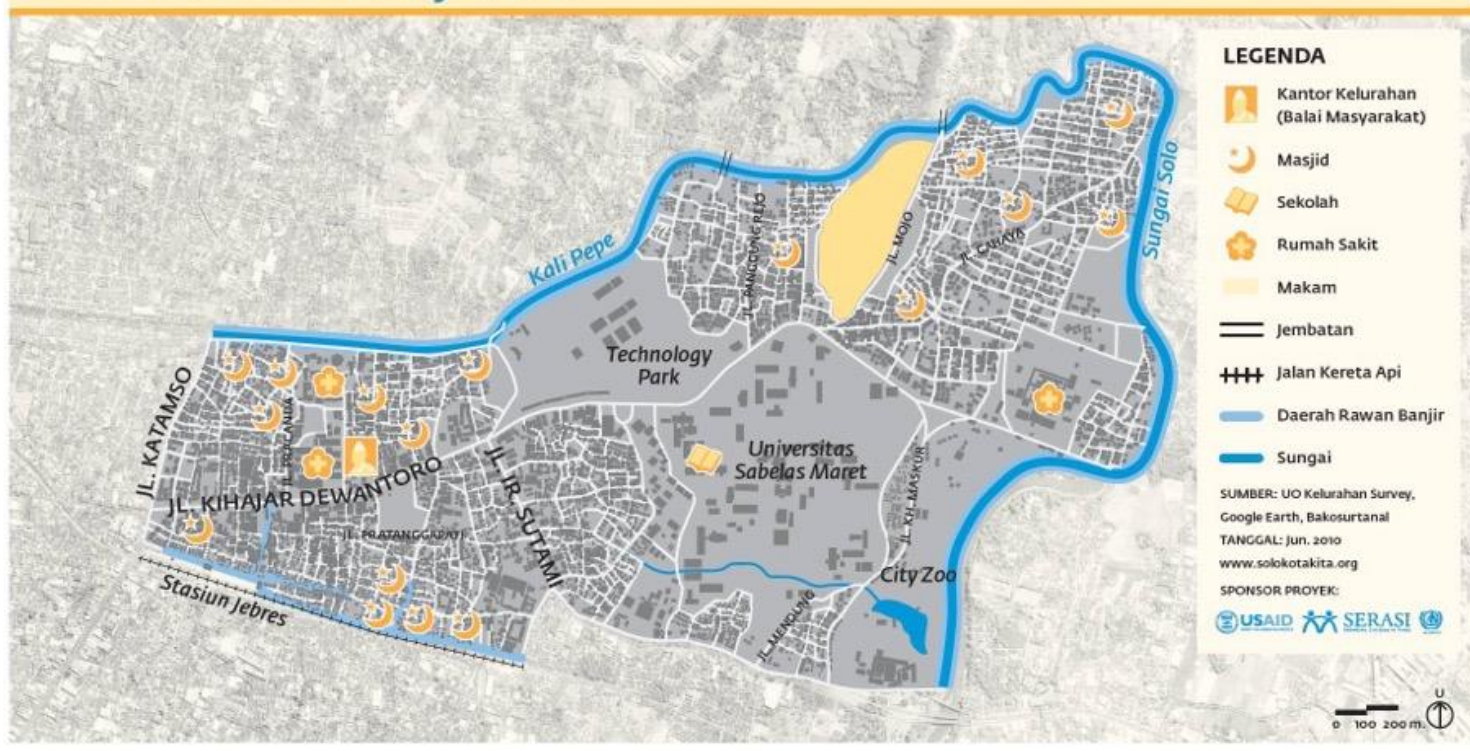

Gambar 10. Kelurahan Jebres, sebagai wilayah lokasi penelitian 


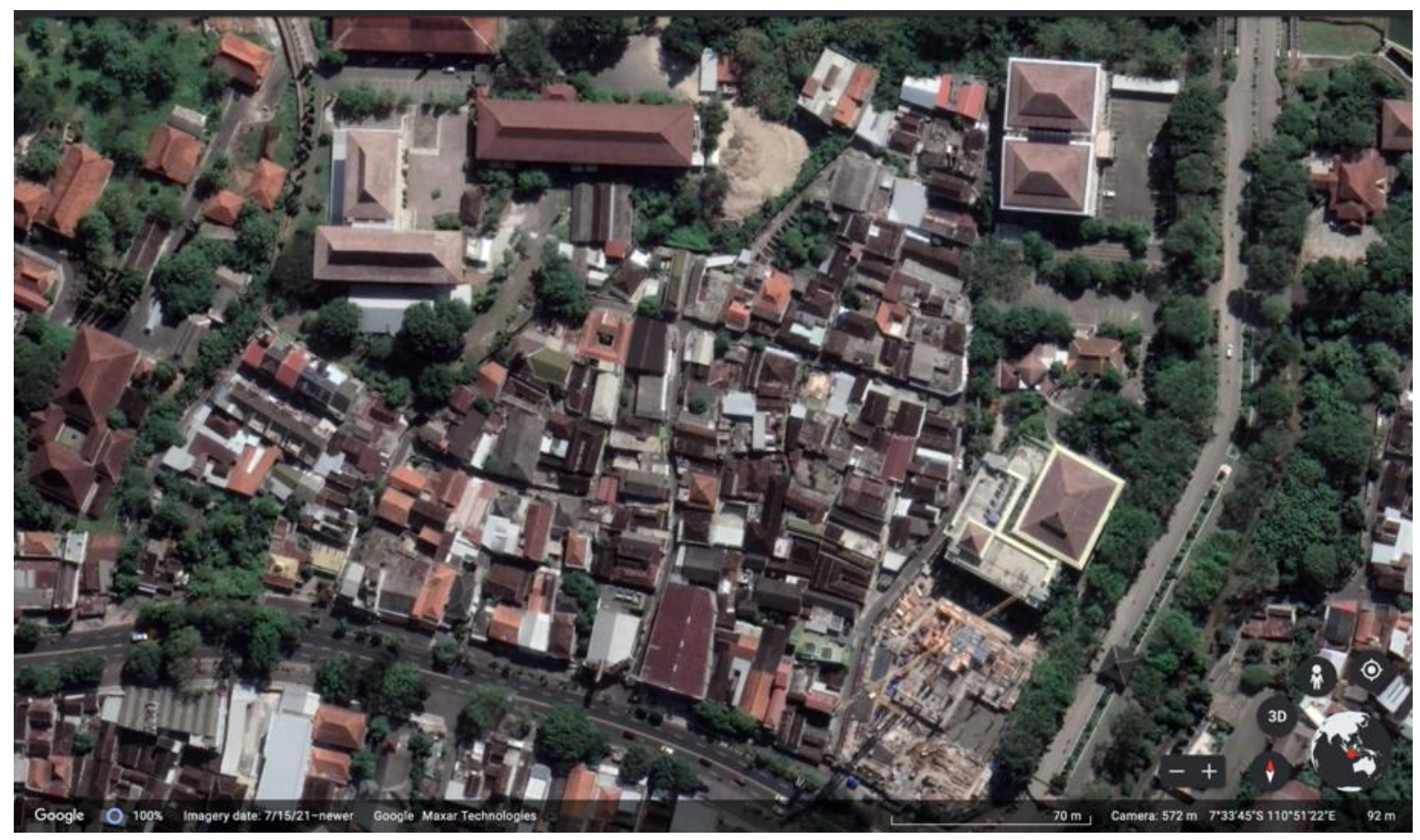

Gambar 11. Lokasi kampung Gendingan RW XV 